\title{
Efeito da fotoexposição na atividade antimicrobiana de basidiomicetos amazônicos ${ }^{1}$
}

\author{
Effect of photoexposure on antimicrobial activity of Amazonian basidiomycetes \\ Efecto de la fotoexposición sobre la actividad antimicrobiana de basidiomicetos amazónicos
}

Recebido: 20/10/2021 | Revisado: 30/10/2021 | Aceito: 01/11/2021 | Publicado: 02/11/2021

\author{
Karen Kelly Carvalho de Oliveira \\ ORCID: https://orcid.org/0000-0002-4946-6886 \\ Instituto Nacional de Pesquisas da Amazônia, Brasil \\ E-mail: karen_kelly_@msn.com \\ Thaíssa Cunha de Oliveira \\ ORCID: https://orcid.org/0000-0003-3124-8124 \\ Instituto Nacional de Pesquisas da Amazônia, Brasil \\ E-mail: thaissa.olcunha@gmail.com \\ Ormezinda Celeste Cristo Fernandes \\ ORCID: https://orcid.org/0000-0001-5752-5017 \\ Fundação Oswaldo Cruz - Instituto Leônidas e Maria Deane, Brasil \\ E-mail: ormezinda.fernandes@ fiocruz.br \\ Pedro Queiroz Costa Neto \\ ORCID: https://orcid.org/0000-0002-1907-7492 \\ Universidade Federal do Amazonas, Brasil \\ E-mail: senaneto16@yahoo.com.br \\ Maria Aparecida de Jesus \\ ORCID: https://orcid.org/0000-0003-3124-8124 \\ Instituto Nacional de Pesquisas da Amazônia, Brasil \\ E-mail: ranhna@gmail.com \\ Luiz Antonio de Oliveira \\ ORCID: https://orcid.org/0000-0002-2008-7292 \\ Instituto Nacional de Pesquisas da Amazônia, Brasil \\ E-mail: luiz.oliveira@inpa.gov.br
}

\begin{abstract}
Resumo
Os microrganismos são uma promissora fonte de novas moléculas e uma boa alternativa na busca por antimicrobianos. Contudo, suas condições de cultivo podem influenciar tanto no seu desenvolvimento quanto na sua produção de biomoléculas. O objetivo deste trabalho foi avaliar o efeito da fotoexposição na atividade antimicrobiana de oito basidiomicetos. Estes foram cultivados em meio ágar-malte, à temperatura ambiente, mantidos com ou sem fotoexposição por dez dias. Foram obtidos extratos com acetato de etila, que foram testados pelo método de difusão em ágar contra os patógenos Escherichia coli CBAM 001, Staphylococcus aureus CBAM 0324 e Candida albicans CFAM 1342. Foi realizada a identificação molecular dos basidiomicetos através de amplificação e sequenciamento do fragmento de rDNA. Os fungos Pleurotus sp. 474 e Gloeophyllum sp. 1153 inibiram o crescimento de E. coli CBAM 001, S. aureus CBAM 0324 e C. albicans CFAM 1342. Nenhum desses patógenos foi inibido pelo fungo Schizophyllum commune 1210. A fotoexposição foi essencial para o fungo Earliella scabrosa 1552 inibir o crescimento da $C$. albicans, enquanto a ausência de fotoexposição foi essencial para o fungo Pleurotus sp. 474 inibir o crescimento do S. aureus CBAM 0324 e, os fungos Gloeophyllum sp. 1153, Trametes sp. 1232 e Oudemansiella canarii 1528 inibirem a E. coli CBAM 001. Estes resultados mostraram a influência da fotoexposição na produção de antimicrobianos por basidiomicetos, reforçando a importância da escolha das condições de cultivo.
\end{abstract}

Palavras-chave: Fungos amazônicos; Compostos bioativos; Antibacterianos; Antifúngicos.

\begin{abstract}
Microorganisms are a promising source of new molecules and a good alternative in the search for antimicrobials. However, their cultivation conditions can influence both their development and their production of biomolecules. The aim of this work was to evaluate the effect of photoexposure on the antimicrobial activity of eight basidiomycetes. These were grown on malt agar medium, at room temperature, maintained with or without photoexposure for ten days. Extracts were obtained with ethyl acetate, which were tested by the agar diffusion method against the pathogens Escherichia coli CBAM 001, Staphylococcus aureus CBAM 0324 and Candida albicans CFAM 1342. The molecular identification of the basidiomycetes was carried out by amplifying and sequencing the fragment of rDNA. The fungi Pleurotus sp. 474 and Gloeophyllum sp. 1153 inhibited the growth of E. coli CBAM 001, S. aureus CBAM 0324 e $C$.
\end{abstract}

${ }^{1}$ Parte da dissertação da primeira autora no mestrado do PPG Biotecnologia da Universidade Federal do Amazonas. 
albicans CFAM 1342. None of these pathogens were inhibited by the fungus Schizophyllum commune 1210. The photoexposure was essential for the fungus Earliella scabrosa 1552 to inhibit the growth of $C$. albicans, while the absence of photoexposure was essential for the fungus Pleurotus sp. 474 inhibit the growth of S. aureus CBAM 0324 and, the fungi Gloeophyllum sp. 1153, Trametes sp. 1232 and Oudemansiella canarii 1528 inhibit E. coli CBAM 001. These results showed the influence of photoexposure on the production of antimicrobials by basidiomycetes, reinforcing the importance of choosing culture conditions.

Keywords: Amazonian fungi; Bioactive compounds; Antibacterial; Antifungal.

\begin{abstract}
Resumen
Los microorganismos son una fuente prometedora de nuevas moléculas y una buena alternativa en la búsqueda de antimicrobianos. Sin embargo, sus condiciones de crecimiento pueden influir tanto en su desarrollo como en su producción de biomoléculas. El objetivo de este trabajo fue evaluar el efecto de la fotoexposición sobre la actividad antimicrobiana de ocho basidiomicetos. Estos se cultivaron en medio de agar malta, a temperatura ambiente, mantenidos con o sin exposición al sol durante diez días. Se obtuvieron extractos de acetato de etilo, los cuales fueron probados por el método de difusión en agar contra los patógenos Escherichia coli CBAM 001, Staphylococcus aureus CBAM 0324 y Candida albicans CFAM 1342. La identificación molecular de basidiomicetos se realizó mediante amplificación y secuenciación del fragmento de ADNr. Los hongos Pleurotus sp. 474 y Gloeophyllum sp. 1153 inhibió el crecimiento de E. coli CBAM 001, S. aureus CBAM 0324 y C. albicans CFAM 1342. Ninguno de estos patógenos fue inhibido por el hongo Schizophyllum commune 1210. La fotoexposición fue esencial para que el hongo Earliella scabrosa 1552 inhibiera el crecimiento de $C$. albicans, mientras que la ausencia de fotoexposición fue fundamental para el hongo Pleurotus sp. 474 inhiben el crecimiento de S. aureus CBAM 0324 y los hongos Gloeophyllum sp. 1153, Trametes sp. 1232 y Oudemansiella canarii 1528 inhibieron E. coli CBAM 001. Estos resultados mostraron la influência de la fotoexposición en la producción de antimicrobianos por basidiomicetos, lo que refuerza la importancia de elegir las condiciones de cultivo.
\end{abstract}

Palabras clave: Hongos amazónicos; Compuestos bioactivos; Antibacterianos; Antifúngicos.

\title{
1. Introdução
}

A resistência antimicrobiana é uma das maiores ameaças mundiais para a saúde. A utilização de antimicrobianos em humanos e animais ocasiona o surgimento e disseminação de bactérias resistentes, e o seu uso excessivo agrava este quadro consideravelmente. Entretanto, a propagação da resistência microbiana não foi seguida pelo desenvolvimento de novos agentes antimicrobianos (Cheng et al., 2016), o que torna a busca por novas substâncias antimicrobianas crucial e contínua.

Os produtos naturais são os produtores das principais classes de antibióticos existentes, sendo responsáveis por aproximadamente dois terços das terapias antibacterianas usadas clinicamente (Farha \& Brown, 2016). Isso ocorre devido à grande diversidade de espécies de plantas, animais e microrganismos, resultando em grande quantidade e variedade de metabólitos secundários, que desempenharam e podem desempenhar um papel fundamental no processo de descoberta de novos medicamentos (Guo, 2017). Além disso, os produtos naturais possuem propriedades únicas que foram aprimoradas naturalmente por processos evolutivos. Algumas destas, como permeabilidade celular intrínseca, diversidade química e especificidade do alvo, geralmente estão ausentes nas bibliotecas de compostos químicos sintéticos (Farha \& Brown, 2016).

Os basidiomicetos destacam-se por produzirem uma variedade de compostos com propriedades nutricionais e medicinais, como antivirais, antitumorais, antioxidantes, antimaláricos, nematicidas e antimicrobianos (Sandargo et al., 2019). Estes compostos podem ser extraídos a partir do corpo de frutificação, micélio, esporos ou do caldo de cultivo.

Amplamente divulgada no meio científico, a produção de antimicrobianos por estes fungos é relatada no mundo todo para diferentes espécies. Estima-se que existam mais de 30000 espécies pertencentes ao filo Basidiomycota até o momento (He et al., 2019). Em contrapartida, apenas uma pequena percentagem destas espécies teve seus compostos bioativos investigados até agora.

Assim, o objetivo deste trabalho foi verificar a atividade antimicrobiana de oito culturas de basidiomicetos nativas da Amazônia, além de estudar a influência da fotoexposição na produção de antimicrobianos. 


\section{Material e métodos}

\subsection{Material fúngico}

Os fungos usados nesse trabalho foram obtidos da Coleção de Macrofungos de Interesse Agrossilvicultural, do Instituto Nacional de Pesquisas na Amazônia. A coleta foi realizada em diversas localidades de Manaus e Boa Vista.

\subsection{Identificação molecular}

A extração de DNA ribossomal dos basidiomicetos foi realizada segundo metodologia indicada pelo kit de extração Norgen Biotek \#26200. Após este procedimento, foi realizada a Reação de Cadeia em Polimerase (PCR) para a amplificação do fragmento gênico rDNA, utilizando-se as seguintes sequências de nucleotídeos: ITS1 (5' - TCCGTAGGTGAACCTGCGG - 3') e ITS4R (5' - TCCTCCGCTTATTGATATGC - 3'). A PCR teve um volume de $20 \mu \mathrm{L}$ ( $25 \mathrm{mM}$ de $\mathrm{MgCl} 2 ; 2,5 \mathrm{mM}$ de dNTPs; $5,0 \mathrm{pmol} / \mu \mathrm{L}$ de cada iniciador; $5 \mathrm{U} / \mu \mathrm{L}$ de Taq DNA polimerase; e tampão $1 \mathrm{X}$ ) e foi realizada em termociclador BIORAD T100TM (ThermalCycler), seguindo o ciclo: 4 min a $94^{\circ} \mathrm{C}$ (desnaturação), 1 min a $94{ }^{\circ} \mathrm{C}$ (anelamento), 1 min a 50 ${ }^{\circ} \mathrm{C}$ (extensão), 1 min a $72{ }^{\circ} \mathrm{C}$ (extensão final), sendo 34 ciclos no total.

O material genético foi submetido à reação de amplificação com o kit "BigDyeTerminator v3.1 CycleSequencing Kit" (Applied Biosystems®) e o sequenciamento realizado em sequenciador automático Applied Biosystems 3130 XL Genetic Analyzer. A programação para amplificação compreendeu os seguintes ciclos: 1 min a $96{ }^{\circ} \mathrm{C}, 25$ ciclos de desnaturação a 96 ${ }^{\circ} \mathrm{C}$ por 15 seg, anelamento a $60{ }^{\circ} \mathrm{C}$ por 15 seg e extensão a $60{ }^{\circ} \mathrm{C}$ por 4 min. As amostras de DNA foram solubilizadas em solução tampão com formamida, desnaturadas $\left(96^{\circ} \mathrm{C}, 5 \mathrm{~min}\right)$ e analisadas no sequenciador automático.

As sequências da região do rDNA obtidas foram submetidas online para comparação com os dados disponíveis na base de dados do GenBank (http://www.ncbi.nlm.nih.gov/BLAST/) utilizando o modo de pesquisa BLAST.

\subsection{Obtenção dos extratos}

Os basidiomicetos foram inoculados em Erlenmeyers contendo $100 \mathrm{~mL}$ de ágar-malte e incubados à temperatura ambiente $\left( \pm 26{ }^{\circ} \mathrm{C}\right)$, com ou sem fotoexposição, por dez dias. A seguir foram fragmentados e levados para a capela de exaustão, onde $150 \mathrm{~mL}$ de acetato de etila foram depositados em cada Erlenmeyer. Estes permaneceram inertes e sem fotoexposição por três dias para a extração dos compostos. Em seguida, foi realizada filtração simples utilizando gaze com algodão hidrófilo, e os extratos permaneceram na capela até total evaporação do solvente. Para a realização dos testes antimicrobianos, os extratos foram diluídos em Dimetilsulfóxido - DMSO.

\subsection{Microrganismos patogênicos}

As cepas de Escherichia coli CBAM 001, Staphylococcus aureus CBAM 0324 e Candida albicans CFAM 1342 foram cedidas pela Coleção de Bactérias da Amazônia - CBAM e pela Coleção de Fungos da Amazônia - CFAM, ambas da Fundação Oswaldo Cruz de Manaus/AM.

\subsection{Teste de difusão em ágar}

A partir de suspensões celulares recém-preparadas dos patógenos (ajustados à coluna $\mathrm{n}^{\mathrm{o}} 1$ da escala de McFarland), $150 \mu \mathrm{L}$ foram retirados e semeados com auxílio de cotonete estéril na superfície do meio ágar-Sabouraud (C. albicans CFAM 1342) e ágar Mueller-Hinton (E. coli CBAM 001 e S. aureus CBAM 0324). Em seguida, foram perfurados três poços (7 mm) em cada placa, onde foram depositados $100 \mu \mathrm{L}$ de cada extrato. Como controle, foram utilizados discos de papel de filtro contendo cloranfenicol $(5 \mathrm{mg} / \mathrm{mL})$ ou itraconazol $(5 \mathrm{mg} / \mathrm{mL})$ no centro das placas. Além deste, foram realizados controles com aplicação de DMSO e acetato de etila nos poços. As placas com bactérias foram incubadas a $37^{\circ} \mathrm{C}$ durante 24 horas e as placas 
com levedura foram mantidas a $28^{\circ} \mathrm{C}$ durante 48 horas. Após esse período, foi realizada a medição do raio do halo de inibição entre a borda do poço contendo a amostra e a borda da colônia do patógeno.

\section{Resultados e discussão}

\subsection{Caracterização molecular}

As sequências obtidas e comparadas com as depositadas no National Center for Biotechnology Information, identificaram cinco fungos ao nível de gênero, dois em espécie e um não mostrou percentual de similaridade suficiente para determinar sua identificação, por isso foi classificado como pertencente à classe Basidiomycete (Tabela 1).

A identificação molecular de fungos geralmente é feita utilizando-se primers amplificadores da região ITS (Seifert, 2009). Contudo, algumas vezes o resultado obtido não é suficiente para determinar a espécie fúngica, como foi o caso de seis basidiomicetos deste estudo. Para que estes possam ser identificados, é necessário que sejam utilizados outros primers, como o LSU (Rungjindamai et al., 2008; Singh et al., 2013).

Menos frequentemente, outras técnicas moleculares também são utilizadas para validar espécies de basidiomicetos como SSR, RAPD, AFLP, as sequências de rRNA SSU mitocondrial e os genes da citrocomo-oxidase (Avin et al., 2014).

Tabela 1: Comparação das sequências obtidas com as sequências depositadas no banco de dados do National Center for Biotechnology Information.

\begin{tabular}{|c|c|c|c|c|c|}
\hline Cultura & Espécie NCBI & $\begin{array}{c}\text { Similaridade } \\
(\%)\end{array}$ & $\begin{array}{c}\text { Identidade } \\
(\%)\end{array}$ & $\begin{array}{c}\text { Número de acesso } \\
\text { NCBI }\end{array}$ & Táxon \\
\hline \multirow{2}{*}{347} & Schizophyllum commune & 94 & 90 & AF280759.1 & \multirow{2}{*}{ Basidiomycete } \\
\hline & S. commune & 78 & 94 & AF249390.1 & \\
\hline \multirow{2}{*}{474} & Pleurotus ostreatus & 100 & 99 & KC686865.1 & \multirow{2}{*}{ Pleurotus sp. } \\
\hline & P. sapidus & 100 & 99 & HM561982.1 & \\
\hline \multirow[b]{2}{*}{1153} & Gloeophyllum striatum & 93 & 97 & KJ141171.1 & \multirow{2}{*}{ Gloeophyllum sp. } \\
\hline & G. trabeum & 90 & 94 & AY089733.1 & \\
\hline 1210 & S. commune & 100 & 99 & AF280759.1 & S. commune \\
\hline \multirow[b]{2}{*}{1232} & Trametes versicolor & 100 & 99 & FJ608587.1 & \multirow[b]{2}{*}{ Trametes sp. } \\
\hline & T. hirsuta & 100 & 99 & JX501305.1 & \\
\hline \multirow[b]{2}{*}{1528} & Oudemansiella canarii & 89 & 95 & AF321477.1 & \multirow[b]{2}{*}{ O. canarii } \\
\hline & O. canarii & 88 & 95 & AF321479.1 & \\
\hline \multirow{2}{*}{1540} & T. lactinea & 99 & 99 & JX082369.1 & \multirow{2}{*}{ Trametes sp. } \\
\hline & T. cubensis & 99 & 99 & JN164989.1 & \\
\hline 1552 & Earliella scabrosa & 99 & 100 & JN165008.1 & E. scabrosa \\
\hline
\end{tabular}

Fonte: Autores.

\subsection{Atividade antimicrobiana}

Um total de 16 extratos (oito obtidos do cultivo com fotoexposição e oito sem fotoexposição) foi testado quanto à sua ação antimicrobiana pelo teste de difusão em ágar. Dentre estes, apenas o fungo Schizophyllum commune 1210 não inibiu os patógenos testados (Tabela 2). Este resultado pode ter acontecido devido às condições de cultivo inadequadas para que esta linhagem produzisse compostos antimicrobianos, à escolha de extração a partir do micélio e/ou à escolha do solvente utilizado. Mifart et al. (2014) obtiveram extratos a partir dos basidiocarpos de S. commune, testando-os contra diversos patógenos bacterianos e fúngicos, sendo vários deles inibidos por estes extratos. Em um trabalho mais recente, Madhanraj et al. (2019) relataram a extração de compostos antibacterianos a partir do micélio desta espécie, utilizando água quente, acetona e hexano. 
Analisando nosso resultado com o de Mifart et al. (2014) e Madhanraj et al. (2019), é possível perceber que a escolha do local de extração, seja do corpo de frutificação ou micelial, e do solvente pode influenciar no sucesso da obtenção de compostos antimicrobianos.

Os demais fungos inibiram pelo menos um dos patógenos testados, com destaque para os fungos Pleurotus sp. 474 e Gloeophyllum sp. 1153, que inibiram todos os patógenos.

Os fungos do gênero Pleurotus e Trametes são reportados na literatura como produtores de antimicrobianos. Contudo, a maioria dos relatos é sobre a extração de compostos a partir do basidiocarpo destes fungos. Na tabela 2 é possível observar que o Pleurotus sp. 474 inibiu E. coli CBAM 001, S. aureus CBAM 0324 e C. albicans CFAM 1342. Há relatos de atividade antibacteriana na literatura para as espécies $P$. ostreatus, $P$. eryngii, $P$. flabellatus, $P$. florida, $P$. pulmonarius, $P$. ostreatoroseus, P. levis, P. tuber-regium, P. sajor-caju, entre outras (Correa et al., 2015; Adebayo et al., 2018; Kandasamy et al., 2019; Madhanraj et al., 2019).

O isolado Trametes sp. 1232 inibiu o crescimento de E. coli CBAM 0001, enquanto Trametes sp. 1540 inibiu $C$. albicans CFAM 1342, com halos mais proeminentes. Gebreyohannes et al. (2019) relataram a ação inibitória de extratos do basidiocarpo de duas linhagens de Trametes sp. contra vários patógenos, incluindo E. coli e C. albicans, demonstrando que essa propriedade é característica deste gênero.

Apesar de algumas vezes os extratos obtidos de basidiocarpos possuírem um espectro antimicrobiano mais vasto, a prática de coletar espécies de basidiomicetos na natureza para extração de compostos em ampla escala não é viável. Uma alternativa a este problema é o cultivo destas espécies em laboratório, realizando o crescimento micelial em meio sólido ou o submerso, sendo o primeiro método escolhido para este trabalho.

Tabela 2: Atividade antimicrobiana de extratos obtidos do cultivo de basidiomicetos em meio ágar malte.

\begin{tabular}{|c|c|c|c|c|}
\hline \multirow[b]{2}{*}{ Identificação } & \multirow[b]{2}{*}{ Condição } & \multicolumn{3}{|c|}{ Diâmetro dos halos de inibição (mm) } \\
\hline & & $\begin{array}{l}\text { E. coli CBAM } \\
001\end{array}$ & $\begin{array}{c}\text { S. aureus } \\
\text { CBAM 0324 }\end{array}$ & $\begin{array}{c}\text { C. albicans } \\
\text { CFAM } 1342\end{array}$ \\
\hline \multirow{2}{*}{ Basidiomycete 347} & $\mathrm{~L}$ & 1,7 & $0,0^{*}$ & 3,0 \\
\hline & $\mathrm{E}$ & 1,7 & $0,0^{*}$ & 3,5 \\
\hline \multirow{2}{*}{ Pleurotus sp. 474} & $\mathrm{~L}$ & 2,0 & $0,0^{*}$ & 3,8 \\
\hline & $\mathrm{E}$ & 2,3 & 3,5 & 3,1 \\
\hline \multirow{2}{*}{ Gloeophyllum sp. 1153} & $\mathrm{~L}$ & $0,0^{*}$ & 3,3 & 3,8 \\
\hline & $\mathrm{E}$ & 2,0 & 3,2 & 3,1 \\
\hline \multirow{2}{*}{$\begin{array}{l}\text { Schizophyllum commune } \\
1210\end{array}$} & $\mathrm{~L}$ & $0,0^{*}$ & $0,0^{*}$ & $0,0^{*}$ \\
\hline & $\mathrm{E}$ & $0,0^{*}$ & $0,0^{*}$ & $0,0^{*}$ \\
\hline \multirow[b]{2}{*}{ Trametes sp. 1232} & $\mathrm{~L}$ & $0,0^{*}$ & $0,0^{*}$ & $0,0^{*}$ \\
\hline & $\mathrm{E}$ & 1,7 & $0,0^{*}$ & $0,0^{*}$ \\
\hline \multirow{2}{*}{ Oudemansiella canarii 1528} & $\mathrm{~L}$ & $0,0^{*}$ & $0,0^{*}$ & 3,8 \\
\hline & $\mathrm{E}$ & 2,3 & $0,0^{*}$ & 4,6 \\
\hline \multirow[b]{2}{*}{ Trametes sp. 1540} & $\mathrm{~L}$ & $0,0^{*}$ & $0,0^{*}$ & 3,5 \\
\hline & $\mathrm{E}$ & $0,0^{*}$ & $0,0^{*}$ & 4,2 \\
\hline \multirow{2}{*}{ Earliella scabrosa 1552} & $\mathrm{~L}$ & 1,5 & $0,0^{*}$ & 2,9 \\
\hline & $\mathrm{E}$ & 2,0 & $0,0^{*}$ & $0,0^{*}$ \\
\hline
\end{tabular}

Condições: L - expostos à luz ambiente; E: cultivado na ausência de luz

Ec: Escherichia coli CBAM 001; Sa: Staphylococcus aureus CBAM 0324; Ca: Candida albicans CFAM 1342.

*Sem halo de inibição aparente (visível)

Fonte: Autores. 
O fungo Earliella scabrosa 1552 apresentou atividade antimicrobiana contra E. coli CBAM 001 e C. albicans CFAM 1342 (Tabela 2). Liew et al. (2015) relataram atividade antibacteriana deste fungo contra $E$. coli, porém os extratos foram obtidos a partir de seu basidiocarpo. A atividade anti-Candida ainda não foi citada na literatura, porém a atividade antifúngica desta espécie foi relatada por Peng e Don (2013), que testaram extratos desta espécie contra fungos degradadores da seringueira e conseguiram inibi-los, corroborando com a atividade antifúngica encontrada em nosso trabalho.

O isolado Oudemansiella canarii 1528 apresentou o maior halo de inibição contra C. albicans CFAM 1342, além de inibir E. coli CBAM 001 e S. aureus CBAM 0324 (Tabela 2). A atividade antimicrobiana desta espécie foi pouco estudada até o momento, mas há relatos que confirmam os resultados apresentados. Vahidi e Namjoyan (2004) utilizaram acetato de etila para obter extratos a partir do filtrado de $O$. canarii, os quais inibiram os mesmos patógenos que nossa pesquisa. Alves et al. (2013) destacam esta espécie como uma das melhores produtoras de compostos inibidores de leveduras do gênero Candida, principalmente seus extratos metanólicos.

Outro basidiomiceto inibidor de C. albicans CFAM 1342 foi Gloeophyllum sp. 1153, que também inibiu S. aureus CBAM 0324. A atividade antibiótica e antifúngica deste gênero foi pouco relatada até hoje. Rasser et al. (2000) isolaram e identificaram a estrutura química de compostos antibacterianos e antifúngicos de espécies de Gloeophyllum. As espécies pertencentes a este gênero ainda precisam ser estudadas mais detalhadamente, pois fungos com características biotecnológicas promissoras podem estar ineficientemente explorados.

\subsection{Efeito da fotoexposição na atividade antimicrobiana dos basidiomicetos}

A busca por antimicrobianos a partir de microrganismos requer que estes sejam cultivados sob condições adequadas, que permitam a produção do metabólito desejado. Estas condições incluem fonte de carbono, nitrogênio, pH, temperatura, agitação e fotoexposição, as quais devem ser analisadas e escolhidas de acordo com o microrganismo estudado. Estes fatores podem interferir diretamente no sucesso da obtenção de antimicrobianos; por isso, um dos objetivos deste trabalho foi avaliar o efeito da fotoexposição na produção de antimicrobianos dos basidiomicetos.

Os compostos inibidores do crescimento de E. coli CBAM 001 produzidos por Gloeophyllum sp. 1153, Trametes sp. 1232 e O. canarii 1528 não foram detectados quando estes fungos foram cultivados com fotoexposição, assim como os compostos inibidores de S. aureus CBAM 0324 produzidos por Pleurotus sp. 474 (Tabela 2). Para a produção desses compostos é indispensável que estes fungos sejam cultivados sem luz e a extração e armazenamento dos mesmos sejam realizadas nas mesmas condições.

Por outro lado, a fotoexposição foi necessária para que E. scabrosa 1552 produzisse compostos antifúngicos contra $C$. albicans CFAM 1342. Os isolados Basidiomycete 347, Pleurotus 474 e Gloeophyllum sp. 1153 apresentaram ação antifúngica semelhante com e sem fotoexposição, apresentando halos de tamanhos aproximados. Portanto, este fator não precisa ser controlado durante o cultivo destes fungos.

Os isolados O. canarii 1528 e Trametes sp. 1540 não tiveram sua atividade anti-Candida suprimida pela fotoexposição. Contudo, houve diferença no tamanho dos halos, de forma que a melhor condição para produção de antifúngicos foi na ausência de fotoexposição (Figura 1). Nesse caso, pode ter ocorrido um aumento na produção destes compostos, consequentemente aumentando sua concentração, ou podem ter sido produzidos compostos diferentes, o que explicaria a diferença de tamanho dos halos.

Dependendo do patógeno, a fotoexposição não influenciou na produção de antimicrobianos. Foi o caso de Gloeophyllum sp. 1153, que nas duas condições produziu compostos inibidores de S. aureus CBAM 0324 (Figura 2) e $C$. albicans CFAM 1342, com halos semelhantes. 
Figura 1: Extratos inibidores de Candida albicans CFAM 1342. (A) - Oudemansiella canarii 1528, com fotoexposição, (B) O. canarii 1528, sem fotoexposição, (C) - Trametes sp. 1540, com fotoexposição, (D) - Trametes sp. 1540, sem fotoexposição. Discos de papel de filtro contendo itraconazol $(5 \mathrm{mg} / \mathrm{mL})$ no centro das placas.

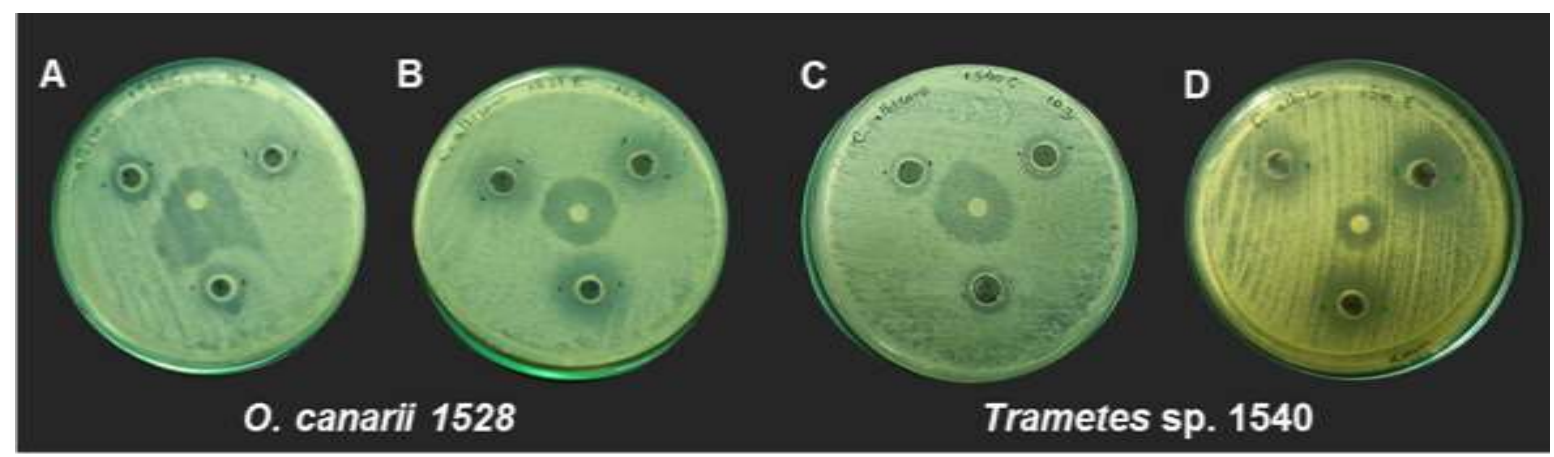

Fonte: Autores.

Figura 2: Extratos inibidores de Staphylococcus aureus CBAM 0324 obtidos do cultivo de Gloeophyllum sp. 1153 em meio sólido, com fotoexposição (A) e sem fotoexposição. Discos de papel de filtro contendo cloranfenicol (5 mg/mL) no centro das placas.

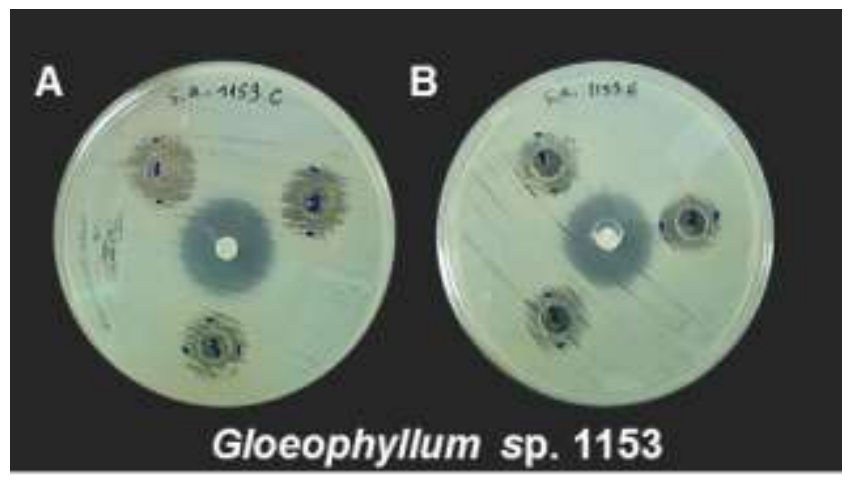

Fonte: Autores.

Estudos de condições de cultivo de basidiomicetos geralmente são realizados para as espécies comestíveis. Porém, este tipo de estudo é igualmente importante para as espécies produtoras de compostos bioativos.

Melo et al. (2009) avaliaram diferentes condições de cultivo para o basidiomiceto Flammulina velutipes, conhecido produtor de metabólitos antimicrobianos. Estes autores investigaram as fontes de carbono e nitrogênio, temperatura, agitação e dias de incubação e seus resultados demonstraram que houve correlação entre a composição do meio de cultura e a produção de antimicrobianos. As condições de cultivo também influenciaram na produção de antibacterianos de Ganoderma resinaceum, o qual foi cultivado em meios de cultivo de diferentes composições e pHs e em diferentes tempos de crescimento. O fungo produziu compostos anti-Staphylococcus em todas as condições, porém a concentração inibitória mínima para este patógeno foi afetada diretamente pelo tempo de fermentação e concentração de glicose no meio (Jorcin et al., 2017).

\section{Conclusões}

O fungo S. commune 1210 não produziu compostos inibitórios para nenhum dos patógenos testados.

Os fungos Pleurotus sp. 474 e Gloeophyllum sp. 1153 inibiram o crescimento dos patógenos E. coli CBAM 001, S. aureus CBAM 0324 e C. Albicans CFAM 1342. 
A fotoexposição foi essencial para o fungo E. scabrosa 1552 inibir o crescimento da C. albicans CFAM 1342, enquanto a ausência de fotoexposição foi essencial para o fungo Pleurotus sp. 474 inibir o crescimento do $S$. aureus CBAM 0324 e, os fungos Gloeophyllum sp. 1153, Trametes sp. 1232 e O. canarii 1528 inibirem a E. coli CBAM 001.

Os resultados deste trabalho sugerem a possibilidade de utilização de basidiomicetos amazônicos como fontes naturais de antimicrobianos.

\section{Agradecimentos}

Ao CNPq (Conselho Nacional de Desenvolvimento Científico e Tecnológico), CAPES (Coordenação de Aperfeiçoamento de Pessoal de Nível Superior) e à FAPEAM (Fundação de Amparo à Pesquisa do Estado do Amazonas), pelo apoio financeiro que permitiu realizar essa pesquisa.

\section{Referências}

Adebayo, E. A., Martiínez-Carrea, D., Morales, P., Sobal, M., Escudero, H., Meneses, M. E., Avila-Nava, A., Castillo, I. \& Bonilla, M. (2018) Comparative study of antioxidant and antibacterial properties of the edible mushrooms Pleurotus levis, P. ostreatus, P. pulmonarius and P. tuber-regium. International Journal of Food Science and Technology, 53(5):1316-1330. https://doi.org/10.1111/ijfs.13712

Alves, M. J., Ferreira, I. C. F. R., Dias, J., Teixeira, V., Martins, A. \& Pintado, M. (2013). A review on antifungal activity of mushroom (Basidiomycetes) extracts and isolated compounds. Current Topics in Medicinal Chemistry, 13(21):2648-2659. 10.2174/15680266113136660191

Avin, F. A., Bhassu, S., Tan, Y. S., Shahbazi, P. \& Vikineswary, S. (2014). Molecular Divergence and Species Delimitation of the Cultivated Oyster Mushrooms: Integration of IGS1 and ITS. The Scientific World Journal, 2014:1-10. https://doi.org/10.1155/2014/793414

Cheng, G., Dai, M., Ahemd, S., Hao, H., Wang, X. \& Yuan, Z. (2016). Antimicrobial drugs in fighting against antimicrobial resistance. Frontiers in Microbiology, 7(470):1-27. 10.3389/fmicb.2016.00470

Correa, R. C. G., Souza, A. H. P., Calhelha, R. C., Barros, L., Glamoclija, J., Sokovic, M., Peralta, R. M., Bracht, A. \& Ferreira, I. C. F. R. (2015). Bioactive formulations prepared from fruiting bodies and submerged culture mycelia of the Brazilian edible mushroom Pleurotus ostreatoroseus Singer. Food \& Function, 6(7):2155-2164. 10.1039/c5fo00465a

Farha, M. A. \& Brown, E. D. (2016). Strategies for target identification of antimicrobial natural products. Natural Products Reports, 33(5):668-680. $10.1039 / \mathrm{c} 5 \mathrm{np} 00127 \mathrm{~g}$

Gebreyohannes, G., Nyerere, A., Bii, C. \& Sbhatu, D. B. (2019). Determination of Antimicrobial Activity of Extracts of Indigenous Wild Mushrooms against Pathogenic Organisms. Evidence-Based Complementary and Alternative Medicine, 2019:1-7. https://doi.org/10.1155/2019/6212673

Guo, Z. (2017). The modification of natural products for medical use. Acta Pharmaceutica Sinica B, 7(2):119-136, 2017. 10.1016/j.apsb.2016.06.003

He, M. Q., Zhao, R.L., Hyde, K. D., Begerow, D., Kemler, M., Yurkov, A. et al. (2019). Notes, outline and divergence times of Basidiomycota. Fungal Diversity, 99:105-367. https://doi.org/10.1007/s13225-019-00435-4

Kandasamy, S., Chinnappan, S., Thangaswamy, S., Balakrishnan, S. \& Khalifa, A. Y. Z. (2019). Assessment of Antioxidant, Antibacterial Activities and Bioactive Compounds of the Wild Edible Mushroom Pleurotus sajor-caju. International Journal of Peptide Research and Therapeutics, 26:1575-1581. https://doi.org/10.1007/s10989-019-09969-2

Jorcin, G., Barneche, S., Vázquez, A., Cerdeiras, M. P. \& Alborés, S. (2017). Effects of Culture Conditions on Antimicrobial Activity of Ganoderma resinaceum (Agaricomycetes) Extracts. International Journal of Medicinal Mushrooms, 19(8):737-744. 10.1615/IntJMedMushrooms.2017021217

Liew, G. M., Khong, H. Y. \& Kutoi, C. J. (2015). Phytochemical Screening, Antimicrobial and Antioxidant Activities of Selected Fungi from Mount Singai, Sarawak, Malaysia. International Journal of Research Studies in Biosciences, 3(1)191-197.

Madhanraj, R., Ravikumar, K., Maya, M. R., Ramanaiah, I., Venkatakrishna, K., Rameshkumar, K., Veeramanikandan, V., Eyini, M., \& Balaji, P. (2019). Evaluation of anti-microbial and anti-haemolytic activity of edible basidiomycetes mushroom fungi. Journal of Drug Delivery and Therapeutics, 9(1):132135, 2019. https://doi.org/10.22270/jddt.v9i1.2277

Melo, M. R., Paccola-Meirelles, L. D., Faria, T. J. \& Ishikawa, N. K. (2009). Influence of Flammulina velutipes mycelia culture conditions on antimicrobial metabolite production. Mycoscience, 50(1):78-81. https://doi.org/10.1007/S10267-008-0447-Z

Mirfat, A. H. S., Noorlidah, A. \& Vikineswary, S. (2014). Antimicrobial activities of split gill mushroom Schizophyllum commune Fr. American Journal of Research Communication, 2(7):113-124.

Peng, T. Y. \& Don, M. M. (2013). Antifungal Activity of In-vitro Grown Earliella scabrosa, a Malaysian Fungus on Selected Wood-degrading Fungi of Rubberwood. Journal of Physical Science, 24(2):21-33.

Rasser, F., Anke, T. \& Sterner, O. (2000). Secondary metabolites from a Gloeophyllum species. Phytochemistry, 54(5):511-516. https://doi.org/10.1016/S0031-9422(00)00137-0 
Research, Society and Development, v. 10, n. 14, e320101422069, 2021

(CC BY 4.0) | ISSN 2525-3409 | DOI: http://dx.doi.org/10.33448/rsd-v10i14.22069

Rungjindamai, N., Pinruan, U., Choeyklin, R., Hattori, T. \& Jones, E. B. G. (2008). Molecular characterization of basidiomycetous endophytes isolated from leaves, rachis and petioles of the oil palm, Elaeis guineensis, in Thailand. Fungal diversity, 33:139-161, 2008.

Sandargo, B., Chepkirui, C., Cheng, T., Chaverra-Muñoz, L., Thongbai, B., Stadler, M. \& Hüttel, S. (2019). Biological and chemical diversity go hand in hand: Basidiomycota as source of new pharmaceuticals and agrochemicals. Biotechnology Advances, 37(6):1-33. https://doi.org/10.1016/j.biotechadv.2019.01.011

Seifert, K. A. (2009). Progress towards DNA barcoding of fungi. Molecular Ecology Resources, 9, Suppl.1, p.83-89. https://doi.org/10.1111/j.17550998.2009.02635.x

Singh, P. K., Kathuria, S., Agarwal, K., Gaur, S. N., Meis, J. F. \&Chowdhary, A. (2013). Clinical Significance and Molecular Characterization of Nonsporulating Molds Isolated from the Respiratory Tracts of Bronchopulmonary Mycosis Patients with Special Reference to Basidiomycetes. Journal of Clinical Microbiology, 51(10):3331-3337. 10.1128/JCM.01486-13

Vahidi, H. \& Namjoyan, F. (2004). Evaluation of Antimicrobial Activity of Oudemansiella sp. (Basidiomycetes). Iranian Journal of Pharmaceutical Research, 3(2):115-117. 10.22037/IJPR.2010.586 